\title{
Panic \& Plaques: Panic Disorder \& Coronary Artery Disease in Patients with Chest Pain
}

\section{David Katerndabl, MD, MA}

Background: The purpose of this systematic review was to identify characteristics of the chest pain associated with the presence of panic disorder, to determine the strength of the association between panic disorder and coronary artery disease (CAD), and to determine the association between panic disorder and known cardiovascular risk factors.

Methods: Potential studies were identified via computerized search using MEDLINE and PSYCINFO databases, and review of bibliographies. MeSH headings used included "panic disorder" with "chest pain," "panic disorder" with "coronary disease or cardiovascular disorders or heart disorders," and "panic disorder" with "cholesterol or essential hypertension or tobacco smoking." Studies had to base their diagnosis of panic disorder on criteria from the Diagnostic and Statistical Manual of Mental Disorders, 4 th Edition, and objective criteria of CAD and risk factors had to be used. Only case-control and cohort studies were included.

Results: The relative risk of panic disorder in patients with nonanginal chest pain is 2.03 [confidence interval (CI), 1.41 to 2.92]. Concerning the relationship between panic disorder and CAD, studies conducted in emergency departments found a relative risk of 1.25 (CI, 0.87 to 1.80). However, there is an inverse relationship between the prevalence of CAD in the study and the prevalence of panic disorder among the patients with CAD $(r=-.469, P=.086)$. Panic disorder has also been linked to cardiac risk factors.

Conclusions: Panic disorder and CAD are correlated in noncardiology settings, and recurrent panic attacks may actually cause CAD. Recognition of either condition should lead the family physician to consider the other, resulting in increased vigilance and possible screening. (J Am Board Fam Pract 2004; 17:114-26.)

Chest pain is a common symptom in primary care populations, reported in $7 \%$ to $24 \%$ of patients, ${ }^{1-3}$ $4.8 \%$ of whom are referred, usually to cardiologists. ${ }^{4}$ In addition, the presence of chest pain in primary care patients is associated with poorer functional status, especially in role functioning. ${ }^{3}$ Not surprisingly, chest pain results in substantial use of resources; $83 \%$ of primary care patients with chest pain receive diagnostic testing, at a mean cost of $\$ 272$ per evaluation. Only $6 \%$ of these evaluations lead to an organic diagnosis, so the average testing cost per organic diagnosis made is $\$ 4354 .{ }^{1}$

Submitted, revised, 20 August 2003.

From the Department of Family and Community Medicine, The University of Texas Health Science Center at San Antonio. Address correspondence to David Katerndahl, MD, Division of Community Geriatrics, Department of Family and Community Medicine, University of Texas Health Science Center at San Antonio, 7703 Floyd Curl Drive, San Antonio, TX 78229 (e-mail: katerndahl@ uthscsa.edu).
Although among primary care patients with chest pain a cardiac diagnosis is made $8 \%$ to $34 \%$ of the time and a psychiatric diagnosis is made $6 \%$ to $37 \%$ of the time, ${ }^{1,5-7}$ the cause of the chest pain is frequently not determined. ${ }^{1}$

The literature on the consequences of chest pain and its relationship to anxiety disorders is extensive; most studies of patients with chest pain include adults ranging in age from 20 to 80 with means from 40 to 60 years. Comparing chest pain patients referred for angiograms with and without cardiac disease, both groups use similar coping strategies. ${ }^{8}$ However, the patients without significant coronary disease on angiography have significantly higher rates of emergency department utilization. ${ }^{9}$ Studies of chest pain patients with normal coronary angiograms report that $13 \%$ of these patients have symptoms of angina and $73 \%$ have atypical angina. Even after such patients are told the normal results of their angiography, $60 \%$ continue to have chest 
Table 1. Prevalence of Panic Disorder in Patients with Chest Pain

\begin{tabular}{|c|c|}
\hline Setting & $\begin{array}{l}\text { Prevalence of } \\
\text { Panic Disorder }\end{array}$ \\
\hline Family practice $^{7}$ & $25 \%$ \\
\hline $\begin{array}{l}\text { Emergency department }{ }^{17,18} \\
\text { Atypical chest pain }{ }^{19,20}\end{array}$ & $\begin{array}{l}18 \%-26 \% \\
16 \%-47 \%\end{array}$ \\
\hline $\begin{array}{l}\text { Referral population } \\
\text { GI Lab (no CAD) } \\
\text { Cardiology } \\
\text { Negative work-up } \\
\text { For cardiac testing } \\
\text { For } \\
\text { For angiography }\end{array}$ & $\begin{array}{c}34 \% \\
38 \% \\
27 \%-37 \% \\
47 \% \\
10 \%\end{array}$ \\
\hline $\begin{array}{l}\text { Cardiology }{ }^{26-28} \\
\text { Sent for } \mathrm{ECG}^{22,29} \\
\text { No CAD } \\
\text { With atypical chest pain }{ }^{31,32} \\
\text { Clinic with nonischemic pain } \\
\text { Cin }\end{array}$ & $\begin{array}{c}9 \%-57 \% \\
62 \% \\
34 \%-41 \% \\
41 \%-59 \% \\
22 \%\end{array}$ \\
\hline Coronary care unit ${ }^{34}$ & $31 \%$ \\
\hline $\begin{array}{l}\text { Other } \\
\text { Minimal/no CAD }{ }^{35,36} \\
\text { Noncardiac chest pain }{ }^{37} \\
\text { Cardiac neurosis }\end{array}$ & $\begin{array}{c}30 \%-43 \% \\
53 \% \\
17 \%\end{array}$ \\
\hline
\end{tabular}

pain, $17 \%$ are rehospitalized, and $30 \%$ limit their physical activity. ${ }^{10}$

Many primary care patients with chest pain have anxiety disorders. ${ }^{3}$ Chest pain patients referred to gastroenterology after cardiology evaluation who have no cardiac or esophageal disease have high rates of panic disorder, obsessive-compulsive disorder, and somatic anxiety. ${ }^{11}$ However, patients with chest pain often assume that their pain is related to coronary artery disease (CAD). This explains why community- and psychiatry practice-based persons with panic attacks have frequently used cardiologists. ${ }^{12-14}$ Yet psychiatry patients with panic disorder are often more distressed than those with cardiac disease, report poorer role functioning than patients with congestive heart failure or after myocardial infarction, and poorer vitality and social functioning than patients after myocardial infarction. ${ }^{15}$

Thus, it is particularly important (and difficult) to distinguish between chest pain caused by panic disorder and that caused by CAD. But are panic disorder and CAD independent?

\section{Chest Pain and Panic Disorder}

Panic disorder is closely linked to chest pain. Chest pain is a common symptom in community-based patients with panic disorder and is included in the definitional criteria for panic disorder. ${ }^{16}$ Table $1^{7,9,17-38}$ presents the prevalence of panic disorder in patients with chest pain. The prevalence of panic attacks, which fail to meet the criteria for panic disorder, is just as high. $7,19,23,26$

Although panic disorder is commonly seen in patients with chest pain, the variability of chest pain during panic attacks may explain why physicians often fail to recognize panic disorder in patients seeking care for chest pain. In one study, none of the $26 \%$ of patients with panic disorder who presented to the emergency department with chest pain were correctly diagnosed. ${ }^{18}$ A similar study in a family practice setting found that only 4 of 26 (15\%) patients presenting with chest pain were recognized as such, whereas 2 were diagnosed with coronary artery disease. However, 12 (46\%) were recognized as having chest pain caused by anxiety or stress. ${ }^{7}$ Aikens et $\mathrm{al}^{39}$ have shown that primary care physicians are capable of differentiating between panic disorder and cardiac disease, although this study did not focus on patients with chest pain.

The recognition of panic attacks in patients presenting with chest pain is critical if serious complications are to be avoided. The presence of chest pain during panic attacks has been linked to the presence and severity of phobic avoidance among community-dwelling persons (as opposed to hospitalized persons) with panic attacks, ${ }^{40}$ and the severity of the chest pain has been associated with decreased life satisfaction and quality of life in community-dwelling individuals with panic attacks ${ }^{41}$ and poor health status in emergency department patients presenting with chest pain. ${ }^{42}$ In addition, $60 \%$ of chest pain patients with recent suicidal ideation who present to emergency departments have panic disorder. ${ }^{43}$ Health care utilization is also affected. Community-dwelling patients with panic attacks cite their chest pain or belief that they are having a "heart attack" as the reason for seeking care $9 \%$ of the time. ${ }^{44}$ Chest pain during panic attacks is linked to increased hospitalization among emergency department patients ${ }^{42}$ and emergency department use, ${ }^{45}$ as well as utilization of personal physicians, ${ }^{45}$ family physicians, and psychiatrists among community-dwelling individuals. ${ }^{13}$ Patients with chest pain referred for angiography use more medications if panic disorder is present. ${ }^{35}$ Failure to recognize panic disorder in patients presenting with chest pain is associated with increased overall health care utilization ${ }^{46}$ and increased laboratory testing in community-based individuals, ${ }^{46,47}$ and higher follow-up visit costs in family practice pa- 
tients, ${ }^{7}$ but fewer mental health referrals among patients in community and emergency department settings. ${ }^{19,46,47}$ In addition, failure to recognize panic is associated with fewer psychotropic medications prescribed in family practice and emergency department settings, ${ }^{7,46,47}$ yet $22 \%$ of primary care patients with chest pain are treated with cardiac medications. ${ }^{7}$ Thus, chest pain in panic disorder and failure to recognize panic are associated with serious consequences in terms of phobic avoidance, quality of life, and health care utilization.

The purpose of this systematic review of the relationship between panic disorder and CAD in patients with chest pain was to identify characteristics of the chest pain associated with the presence of panic disorder, to determine the strength of the association between panic disorder and CAD, and to determine the association between panic disorder and known cardiovascular risk factors.

\section{Methods}

\section{Retrieval of the Literature}

Potential studies were identified via computerized search of studies using MEDLINE and PSYCINFO databases as well as via review of bibliographies and reference lists of papers. Searches were not limited by study design or type of publication. The MeSH headings searched included "panic disorder" with "chest pain," "panic disorder" with "coronary disease or cardiovascular disorders or heart disorders," and "panic disorder" with "cholesterol or essential hypertension or tobacco smoking." These 3 searches yielded 146, 117, and 121 articles, respectively.

\section{Selection of the Literature}

Only case control and cohort studies were included. Inclusion criteria required standard criteria for diagnoses. Hence, studies had to base their diagnosis of panic disorder on criteria from the Diagnostic and Statistical Manual of Mental Disorders (DSM) 4th Edition (see Table 2). In addition, objective criteria relevant to each question had to be used. Standard definitions of angina had to be specified, such as chest pain that was substernal, exertional, and relieved by rest or nitroglycerin. Objective criteria for coronary artery disease (eg, $>50 \%$ stenosis on angiography) had to be used in studies looking at the relationship between panic disorder and CAD. Finally, objective levels of risk factors (eg, total cholesterol >200) had to be used in studies of risk factors. Abstracts of all potential articles were reviewed, and those seeming to address the inclusion criteria were reviewed in detail.

\section{Analysis}

A standard abstraction form was used that included study design, criteria for diagnoses and exposure, potential confounding variables, the presence of chest pain in subjects, site of the study, and results as $2 \times 2$ tables. No cohort studies were identified. Because this literature comes from several settings (community populations, primary care, emergency departments, cardiology settings), quantitative summaries were only conducted within similar settings. A minimum of 3 studies using standard criteria conducted within similar settings was required before quantitative summary was attempted. Study results were expressed using the natural logarithmic transformation of the relative risk. Weighted means were then calculated using methods described by Greenland. ${ }^{48}$

\section{Results}

\section{Characteristics of Chest Pain}

For most characteristics, there were insufficient numbers of homogeneous studies to quantitatively 
Table 3. Included Studies Assessing the Relationship between Nonanginal Pain and Panic Disorder in Patients Presenting to Emergency Departments for Chest Pain

\begin{tabular}{|c|c|c|c|}
\hline Sample Size & Results & Criteria for 'Angina' & Criteria for 'Panic Disorder' \\
\hline $129^{17}$ & \begin{tabular}{r|r}
19 & $9^{*}$ \\
170 & 1
\end{tabular} & Substernal + Exertional + Relief with NTG/Rest & SCID + \\
\hline $180^{18}$ & \begin{tabular}{l|l}
76 & 14 \\
57 & 33
\end{tabular} & Substernal + Exertional + Relief with NTG/Rest & ADIS \\
\hline $441^{42}$ & \begin{tabular}{l|l}
159 & 27 \\
174 & 81
\end{tabular} & Substernal + Exertional + Relief with NTG/Rest & ADIS \\
\hline
\end{tabular}

* $2 \times 2$ table in which the presence or absence of panic disorder is indicated in the left and right columns, respectively, and the presence or absence of angina is indicated in the top and bottom rows, respectively.

† SCID, structured clinical interview of the DSM; ADIS, anxiety disorders interview schedule.

summarize the relationship between pain characteristics and panic disorder. However, 3 studies $^{17,18,42}$ conducted in emergency departments were sufficiently similar to combine. Table 3 summarizes these studies. The weighted combined results show that the relative risk of panic disorder in patients with nonanginal chest pain is 2.03 (CI, 1.41 to 2.92 ). However, other specific characteristics of the chest pain may help to distinguish between panic disorder and other causes of chest pain. Some characteristics normally thought to indicate coronary disease are associated with anxiety or panic disorder in previous studies, such as the occurrence of chest pain with exertion, a pressure sensation, ${ }^{7,49}$ and a substernal ${ }^{7}$ or precordial location ${ }^{49,50}$ But chest pain with anxiety or panic has also been described as nonexertional, ${ }^{49}$ dyspeptic, ${ }^{21}$ associated with meals ${ }^{21}$ or nervousness, ${ }^{21}$ present at night, ${ }^{7}$ and located in the chest wall, ${ }^{50}$ right hand ${ }^{27}$, or forearm but not in the left back. ${ }^{18}$ Exertional pattern and relief with nitroglycerin have poor predictive validity for CAD in primary care settings. ${ }^{51}$

Table 4. Included Studies Assessing the Association between Panic Disorder and Coronary Artery Disease in Patients with Chest Pain

\begin{tabular}{|c|c|c|c|c|c|}
\hline Setting & $\begin{array}{l}\text { Sample } \\
\text { Size }\end{array}$ & Res & ults & Criteria for 'CAD' & $\begin{array}{l}\text { Criteria For } \\
\text { 'Panic Disorder' }\end{array}$ \\
\hline \multirow[t]{3}{*}{ Emergency department } & $229^{17}$ & $\frac{135}{54}$ & $\frac{27^{*}}{13}$ & $\begin{array}{l}\text { Abnormal angiogram or ETT }+ \text { /acute MI by EKG or } \\
\text { enzyme criteria/history of MI or abnormal cardiac } \\
\text { evaluation }\end{array}$ & SCID \\
\hline & $180^{18}$ & $\frac{51}{82}$ & $\frac{21}{26}$ & $\begin{array}{l}\text { Previous MI, PTCA, or CABG/angiogram with }>50 \% \\
\text { stenosis/abnormal thallium ETT }\end{array}$ & ADIS \\
\hline & $441^{52}$ & $\frac{284}{49}$ & $\frac{83}{25}$ & $\begin{array}{l}\text { Previous MI, PTCA, or CABG/angiogram with }>50 \% \\
\text { stenosis/abnormal thallium ETT }\end{array}$ & ADIS \\
\hline \multirow[t]{5}{*}{ Cardiology } & $113^{33}$ & $\frac{72}{19}$ & $\frac{20}{2}$ & Abnormal ETT & DIS \\
\hline & $98^{24}$ & $\frac{26}{46}$ & $\frac{23}{3}$ & $\begin{array}{l}\text { No previous CAD/angiogram with }>50 \% \text { Stenosis/ } \\
\text { abnormal ETT }\end{array}$ & DIS \\
\hline & $74^{35}$ & $\frac{16}{43}$ & $\frac{12}{3}$ & No previous CAD/abnormal angiogram & \\
\hline & $30^{53}$ & $\frac{9}{16}$ & $\frac{3}{2}$ & Abnormal thallium ETT & ADIS \\
\hline & $199^{22}$ & $\frac{98}{25}$ & $\frac{69}{7}$ & No previous CAD/abnormal ETT & SCID \\
\hline
\end{tabular}

* $2 \times 2$ table in which the presence or absence of panic disorder is indicated in the left and right columns, respectively, and the presence or absence of CAD is indicated in the bottom and top rows, respectively.

† ADIS, anxiety disorders interview schedule; SCID, structured clinical interview of the DSM; DIS, diagnostic interview schedule; DSM, Diagnostic and Statistical Manual of Mental Disorders; MI, myocardial infarction; ETT, exercise treadmill test; PTCA, percutaneous transluminal coronary angioplasty; CABG, coronary artery bypass graph. 


\section{Association between Panic Disorder and CAD}

Table 4 presents the studies ${ }^{17,18,22,24,33,35,52,53}$ that investigated the association between $\mathrm{CAD}$ and panic disorder, which were conducted on patients with chest pain in emergency departments or cardiology settings. There were insufficient population-based or primary care studies to summarize. Combining studies conducted in emergency departments found a relative risk of 1.25 (CI, 0.87 to 1.80). Cardiology-based studies are difficult. Combining those studies that excluded patients with prior evidence of CAD found a relative risk of 0.19 (CI, 0.10 to 0.37 ), whereas those studies basing the diagnosis of $\mathrm{CAD}$ on either thallium treadmills or angiography found a relative risk of 0.11 (CI, 0.05 to 0.26$)$. However, the selective nature of the samples prevents a strong conclusion about the association between $\mathrm{CAD}$ and panic disorder from being made. Using all 10 studies conducted in patients with chest pain, there is an inverse relationship between the prevalence of CAD in the study and the prevalence of panic disorder among the patients with CAD ( $\mathrm{r}=-.469, P=.086$ ); thus, the more selective the sample, the lower the detected association between panic disorder and CAD.

\section{Association between Panic Disorder and Cardiovascular Risk Factors}

There were insufficient numbers of homogeneous studies to quantitatively summarize the relationship. In addition, none of the studies of the relationship of panic disorder and cardiovascular risk factors were longitudinal, so the evidence of associations is not strong. However, several known cardiac risk factors have been reported to be present in people with panic disorder. Dammen et $\mathrm{al}^{22}$ reported no association with hypertension, diabetes, obesity, or hyperlipidemia, Bajwa et $\mathrm{al}^{54}$ reported no association with BMI, and Roy-Byrne et $\mathrm{al}^{55}$ reported no association with hypercholesterolemia. However, most studies have clearly linked panic disorder to cardiac risk factors. Not only do people with panic disorder frequently have a family history of $\mathrm{CAD}$, but the total number of risk factors is increased as well. ${ }^{22}$

Panic disorder is linked to increases in both systolic and diastolic blood pressures, ${ }^{56,57}$ and the diagnosis of hypertension is associated with both panic disorder ${ }^{28,55,58-61}$ and panic attacks. ${ }^{7,58,62}$
These studies were conducted in the general population and clinical settings (primary care, cardiology, and psychiatry) with sample sizes from $48^{56}$ to $4874^{60}$; all 3 primary care studies ${ }^{55,58,59}$ found an association between panic disorder and hypertension. This may explain why $9 \%$ to $32 \%$ of patients with chest pain and normal coronary angiograms have hypertension. ${ }^{63}$

Similarly, panic disorder is associated with lipid abnormalities. Specifically, total cholesterol levels are increased in those with panic disorder. ${ }^{54,64}$ However, significant associations between panic disorder and hyperlipidemia were found only in psychiatry-based studies of small sample size ${ }^{54,64}$; studies in cardiology $y^{22}$ and primary care settings ${ }^{55}$ involving larger sample sizes have not found this association. If they exist, elevations in cholesterol may be caused by increased catecholamines ${ }^{64}$ and may explain the correlation between total cholesterol and fear of dying in patients with panic disorder. ${ }^{65}$ This is further supported by studies that have documented elevated cholesterol levels in $8 \%$ to $55 \%$ of patients with chest pain and normal coronary angiograms. ${ }^{63}$ Furthermore, women with panic disorder frequently have elevated LDL levels with decreased HDL levels, whereas men with panic disorder frequently have elevated triglyceride levels. ${ }^{64}$ However, elevated LDL levels in patients with anxiety disorders is not limited to those with panic disorder. ${ }^{66}$

Finally, although there are no primary carebased studies, smoking is linked to panic disorder in population-, cardiology-, and psychiatry-based studies with sample sizes from 102 to $3132 .^{22,67,68}$ This may explain why $32 \%$ to $64 \%$ of patients with chest pain and normal coronary angiograms are smokers. ${ }^{63}$ However, the nature of this relationship is unclear. On the one hand, panic attacks are not believed to induce smoking, ${ }^{67}$ even though $19 \%$ of patients with panic disorder report that they increased their smoking because of their panic. ${ }^{68}$ On the other hand, $72 \%$ of panic disorder patients report smoking when their attacks began, with 55\% and $26 \%$ reporting to have decreased or stopped smoking in response to their panic. ${ }^{68}$ Daily or continuous smoking are risk factors for the onset of panic, and the frequency of panic attacks correlates with the amount of smoking. ${ }^{67}$ However, panic attacks have also begun after short-term smoking abstinence. ${ }^{69}$ 


\section{Discussion}

\section{Characteristics of Chest Pain in Panic Disorder}

When looking at specific characteristics of chest pain, panic disorder has frequently been reported in those having atypical angina or atypical chest pain. ${ }^{18-20,31,32,35,42,70,71}$ This review supports these findings. However, panic disorder has also been seen in patients with typical angina (4\% to $65 \%) .{ }^{28,63}$ Further complicating the angina-atypical angina link to panic disorder is that $10 \%$ of patients with ischemic chest pain have panic disorder. ${ }^{33}$ Conversely, only $64 \%$ of patients with heart disease have chest pain, ${ }^{21}$ atypical chest pain is seen in coronary artery disease, ${ }^{32}$ and only $79 \%$ of patients with significant coronary artery disease have angina. ${ }^{9}$ In emergency department patients with acute chest pain, angina was most common in those patients with both panic disorder and acute ischemia. ${ }^{17}$ However, there are studies that have either failed to find an association between panic disorder and angina ${ }^{72}$ or have found no difference in the prevalence of angina and atypical angina (19\%) in patients with panic disorder. ${ }^{33}$ Thus, although certain atypical features may suggest panic disorder, many of the characteristics classically associated with CAD are common in patients with panic disorder or anxiety.

One reason that people with chest pain associated with panic disorder often seek medical care is the distress that accompanies the pain. Patients with panic disorder are emotionally sensitive. ${ }^{16}$ As a group, those with panic attacks are more concerned about pain, are more convinced that they have a disease, and are more phobic about disease and death than control subjects. ${ }^{73}$ Those with fear as part of their attacks have more panic symptoms with a more recent onset. ${ }^{30}$ Panic patients are selectively attentive to heart rate and electrocardiograms. ${ }^{74}$ The significance is that cardiopulmonary fear is the best predictor of the intensity of the cardiac complaints in patients with noncardiac chest pain. ${ }^{75}$ Even when panic disorder and CAD coexist, the distress perceived by patients with chest pain is typically caused by the panic disorder. ${ }^{52}$ On the other hand, highly anxious patients with panic disorder exhibit increased muscular activity in the chest wall after carbon dioxide inhalation, which predicts frightening cognitions. ${ }^{76}$ Thus, it is not surprising that people with chest pain caused by panic attacks readily seek care for their pain.
Table 5. Prevalence of Panic Disorder in Patients with Coronary Artery Disease

\begin{tabular}{|c|c|}
\hline Setting & $\begin{array}{l}\text { Prevalence of } \\
\text { Panic Disorder } \\
{[\%(95 \% \text { CI })]}\end{array}$ \\
\hline $\begin{array}{l}\text { Emergency department } \\
\text { No cardiac cause } \\
{ }^{52}\end{array}$ & $\begin{array}{c}6(3-9) \\
34(23-45)\end{array}$ \\
\hline $\begin{array}{l}\text { Referral populations } \\
\text { GI laboratory } \\
\text { For cardiac testing } g^{24} \\
\text { For angiography }\end{array}$ & $\begin{array}{l}49(37-61) \\
6(0-13) \\
0 \text { (not calculable) }\end{array}$ \\
\hline $\begin{array}{l}\text { Cardiology }{ }^{27,70} \\
\text { Atypical chest pain } \\
\text { Clinic }^{33}\end{array}$ & $\begin{array}{l}22(7-37), 27(14-40) \\
52(34-70) \\
10(0-23)\end{array}$ \\
\hline $\begin{array}{l}\text { Other } \\
\text { General }^{35} \\
\text { Post-myocardial infarction }^{78} \\
\text { Microvascular angina }\end{array}$ & $\begin{array}{c}7(0-14) \\
6(1-11) \\
40(15-65)\end{array}$ \\
\hline
\end{tabular}

\section{Panic Disorder and Cardiac Disease}

This review failed to document an association between panic disorder and CAD. However, the less selective the sample, the higher the prevalence of panic disorder in CAD patients. Tables $5^{*}$ and $6^{18,28,32,34,35,55,60}$ show, respectively, that panic disorder occurs in $0 \%$ to $53 \%$ of patients with $\mathrm{CAD}$ and that $\mathrm{CAD}$ occurs in $4 \%$ to $55 \%$ of patients with panic disorder. Although panic disorder is usually more common in people without CAD than those with $\mathrm{CAD},{ }^{24,25,27,32}$ it is still seen in a significant portion of those with CAD. In fact, Kane et $\mathrm{al}^{21}$ found more panic disorder in patients with $\mathrm{CAD}$ than without it.

The comorbidity between CAD and panic disorder can have serious consequences. Not only can diagnosing panic disorder result in failure to recognize CAD, but panic disorder itself is often unrecognized, ${ }^{36,43}$ leading to increased social disability, medical costs, and disease progression. ${ }^{36}$ Men with panic disorder have an increased rate of cardiovascular mortality. ${ }^{80}$ The tachycardia observed during a panic attack could potentially lead to an acute myocardial infarction in someone with underlying CAD. This may reflect the increased sudden death and fatal cardiovascular disease observed in patients with anxiety in general. ${ }^{81}$

In addition to $\mathrm{CAD}$, panic disorder is associated with other cardiac abnormalities. Patients with panic disorder have elevated standing heart rates ${ }^{82}$,

${ }^{*}$ References 17, 21, 24, 25, 27, 32, 33, 35, 52, 70, 77-79. 
Table 6. Prevalence of Coronary Artery Disease in Patients with Panic Disorder

\begin{tabular}{ll}
\hline Setting & $\begin{array}{c}\text { Prevalence of CAD } \\
{[\%(95 \% \text { CI })]}\end{array}$ \\
\hline Primary Care $^{55}$ & $4(0-8)$ \\
Emergency department $^{18}$ & $55(40-70)$ \\
Cardiology $^{28}$ & $44(30-58)$ \\
Atypical chest pain $^{32}$ & $27(15-39)$ \\
Other $_{\text {General }}^{35}$ & \\
Any cardiovascular disease $^{34,60}$ & $20(0-41)$ \\
\hline
\end{tabular}

and $10 \%$ have an arrhythmia. ${ }^{28}$ Panic disorder has also been associated with increased left ventricular mass and diameter. ${ }^{83}$ In addition, patients with panic disorder have poorer cardiovascular fitness, as demonstrated by lower $\mathrm{Vo}_{2}$ max and decreased exercise tolerance compared with control subjects. ${ }^{84}$ Although panic disorder is reportedly associated with idiopathic cardiomyopathy, ${ }^{85}$ not all studies support this. ${ }^{86,87}$ Panic disorder has also been linked to a descending aortic aneurysm ${ }^{88}$ and pulmonary hypertension caused by an atrial septal defect with pulmonic valve disease. ${ }^{89}$ But the strongest association is with mitral valve prolapse (MVP).

The panic-MVP relationship has been well documented..$^{90}$ However, MVP is not likely to be the source of chest pain. ${ }^{91}$ The significance of the panic-MVP relationship is unclear. The presence of MVP does not alter psychiatric comorbidity ${ }^{92,93}$ or treatment response. ${ }^{94}$ The source of the linkage is also unclear. Although a MVP-to-panic sequence has been proposed, ${ }^{95}$ no evidence supports it. Indirect linkages via autonomic vulnerability or dysfunction have also been made. ${ }^{96}$ It is most likely that the decreased left ventricular volume caused by the tachycardia seen in panic disorder can produce MVP. ${ }^{97}$ The observation that the MVP disappears with remission of the panic disorder further supports this sequence. $^{98}$

Thus, panic disorder has been linked to several forms of cardiac disease. Although a relationship with MVP is probably the most common, the association with CAD is the most significant. Not only does this lead to serious consequences but panic symptoms may also overshadow those of $\mathrm{CAD}$, and the characteristics of the chest pain do not accurately distinguish between them.

\section{Nature of the Panic-CAD Relationship}

Although the source of chest pain in panic disorder could be chest wall activity ${ }^{76}$ or esophageal abnormalities, ${ }^{63}$ the most likely source is ischemia. Assuming that ischemia is the source, 3 possible mechanisms have been proposed as the source of chest pain in panic disorder.

\section{Decreased Heart Rate Variability}

First, patients with panic disorder exhibit decreased heart rate variability. ${ }^{99-102}$ Compared with control subjects, patients with panic disorder display higher maximal heart rates, higher heart rates on standing, and decreased PR intervals, ${ }^{29,56}$ all of which decrease heart rate variability. ${ }^{103}$ Tachycardia and diminished variability can lead to increased oxygen demand and ischemia. ${ }^{77}$ Decreased heart rate variability has also been linked to sudden death. ${ }^{104}$

\section{Microvascular Angina}

A second possible mechanism for ischemia in panic disorder is that of microvascular angina. Under this mechanism, hyperventilation associated with attacks results in increased contractility, stroke volume, and cardiac output. Increased catecholamines lead to increased peripheral resistance. Coupled with spasm of intramyocardial arterioles, this results in microvascular angina and, eventually, cardiomyopathy. ${ }^{57}$ Almost 50\% of women with chest pain but no CAD have microvascular dysfunction unrelated to cardiovascular risk factors. ${ }^{105}$ In fact, $40 \%$ of patients with microvascular angina have panic attacks. Patients with panic disorder and those with microvascular angina have similar results for electrocardiography, exercise treadmill tests, and left ventricular ejection fraction. ${ }^{79}$ As part of Syndrome X, microvascular angina is associated with ongoing chest pain but has an excellent prognosis in terms of mortality. ${ }^{106}$

\section{Coronary Artery Disease}

Panic disorder and CAD often coexist, and the chest pain in panic disorder may be caused by true CAD. Although myocardial ischemia could cause panic attacks via increased catecholamines or cerebral carbon dioxide levels secondary to lactate, ${ }^{107}$ panic disorder is more likely to promote $\mathrm{CAD}$ through its relationship with cardiac risk factors. However, the nature of the relationships between panic disorder and the cardiac risk factors is unclear. Although it has been suggested that smoking 
Table 7. Correlates with Presence of Panic Disorder in Patients with Chest Pain

\begin{tabular}{|c|c|}
\hline Population & Correlates \\
\hline $\begin{array}{l}\text { Emergency } \\
\text { department }\end{array}$ & $\begin{array}{l}\text { Younger age }{ }^{17,18,42} \\
\text { Atypical chest pain }{ }^{18} \\
\text { Elevated levels } \\
\text { Depression }^{42} \\
\text { Anxiety }^{42} \\
\text { Phobia }^{42}\end{array}$ \\
\hline Cardiology & $\begin{array}{l}\text { Demographics } \\
\text { Younger age }^{27} \\
\text { Female }^{27} \\
\text { Unemployed }^{27} \\
\text { Less education }^{27} \\
\text { Lower income } e^{27} \\
\text { Elevated levels } \\
\text { Pain }^{22,27} \\
\text { Hypochondriasis }^{22} \\
\text { Somatosensory amplification } \\
\text { Presence of } \\
\text { Agoraphobia }^{22} \\
\text { GAD }^{22} \\
\text { Major depression }^{22} \\
\text { Somatoform disorder } \\
\text { Personality disorder (bipolar disorder, } \\
\text { avoidant) }^{109}\end{array}$ \\
\hline
\end{tabular}

could cause panic disorder secondary to associated lung disease ${ }^{67}$ and panic disorder has been linked to COPD,${ }^{108}$ the weakness of this association refutes a causal relationship.

\section{Implications}

\section{Recognition of Panic Disorder}

Panic disorder is diagnosed via DSM criteria; although lactate infusion, $\mathrm{CO}_{2}$ inhalation, and hyperventilation can induce panic attacks in research settings, these tests are not sensitive enough to be useful clinically. However, certain patient characteristics can suggest which patients with chest pain should be targeted for screening. Table $7^{17,18,22,27,42,50,109}$ presents correlates with the presence of panic disorder in patients presenting with chest pain. Consistent correlates of panic disorder are younger age, and psychiatric symptoms and diagnoses. Not all studies support the importance of age or gender. ${ }^{17,25,26,31,42}$ Atypical chest pain is also a correlate. ${ }^{31}$ In general, panic disorder should be suspected in patients with chest pain in the presence of atypical pain, lack of organic causes of chest pain, asymptomatic MVP, and palpitations without significant arrhythmia. ${ }^{110}$

Predictive models of panic disorder in emergency department and cardiology patients are 73\% and $78 \%$ correct, respectively. ${ }^{18,27}$ However, the likelihood ratios in these models are not strong enough to recommend them. These models emphasize considering panic disorder in patients with chest pain who are younger, have agoraphobic cognitions, have noncardiac types of pain, and have pain in the right arm.

With these studies considered, which patients presenting to primary care physicians should be screened for panic disorder? First, the high prevalence of panic disorder as documented in Table $1^{7,9,17-38}$ suggests that physicians should have a high index of suspicion for panic disorder in every patient seen with chest pain. Second, certain demographic groups (younger age, female) deserve particular attention. In addition, pain characteristics (atypical chest pain, noncardiac description, pain in the right arm or hand) and agoraphobic cognitions or behaviors should increase the index of suspicion. Patients who lack organic causes of chest pain, who have MVP, or who have normal cardiac testing also deserve attention. These patients should be evaluated for panic disorder using DSM criteria.

If it is still unclear whether the patient has panic disorder, a drug trial may be useful. Although sublingual nitroglycerin may be helpful in angina, the frequent occurrence of esophageal abnormalities in panic disorder ${ }^{111}$ and the response of esophageal spasms to nitroglycerin suggest that response to nitroglycerin would not exclude panic disorder. A trial of high potency benzodiazepines may be helpful. Alprazolam has been shown to decrease chest pain and panic attack frequency in panic disorder patients with chest pain ${ }^{112}$ and clonazepam has been shown to decrease anxiety levels and panic attack frequency in panic disorder patients with chest pain and normal coronary angiograms. However, even a placebo can decrease panic attack frequency. ${ }^{113}$ Similarly, a trial of sertraline may not differentiate disorders because sertraline reduces pain levels in patients with noncardiac chest pain. ${ }^{114}$

\section{If Panic Disorder Is Diagnosed}

Because the presence of panic disorder does not exclude CAD (and, in fact, can be associated with it), which patients with panic disorder should be further evaluated for CAD? The most defensible strategy would probably be to work up any patient with cardiac risk factors, given that patients with both $\mathrm{CAD}$ and panic disorder tend to exhibit distress because of the panic attacks. ${ }^{52}$ Hence, the panic attacks may serve the valuable role of causing 
the patient with CAD to seek care and to alert the physician to the possibility of CAD. Because MVP can produce false-positive results on an exercise tolerance test, a thallium exercise tolerance test is probably the preferred test for CAD in the presence of panic disorder. Because patients with chest pain continue to have symptoms and disability after reassurance ${ }^{115}$ or a normal coronary angiogram, ${ }^{10}$ cardiac work-ups should not be performed with the goal of convincing patients that they have no cardiac disease. The lack of reassurance by patients may explain why only $56 \%$ of emergency department patients with chest pain begun on paroxetine for panic disorder are still taking it 1 month later. ${ }^{116}$

\section{CAD with Panic Disorder}

In the presence of CAD, panic disorder should be treated with a selective serotonin reuptake inhibitor (SSRI), a high-potency benzodiazepine, or cognitive-behavioral therapy. Although tricyclic antidepressants are effective in panic disorder, their cardiotoxicity precludes them as first line agents in the presence of CAD. In addition to possible cardiotoxicity, imipramine therapy for panic disorder has been shown to increase cardiovascular mortality risk secondary to increased blood pressure and heart rate. ${ }^{117}$ Although angina, hypertension, and hypercholesterolemia are rare side effects of SSRI therapy, hypertension is a risk (5\%) in high-dose venlafaxine therapy. ${ }^{118}$ If the patient has multiple cardiac risk factors or an SSRI-exacerbated risk factor, a high-potency benzodiazepine or cognitive-behavioral therapy may be the best choice. Alprazolam has been shown to decrease not only catecholamine response to exercise ${ }^{119}$ but also can actually decrease total cholesterol when used to treat panic disorder. ${ }^{120}$ In addition, although alprazolam did not decrease the frequency or severity of anginal attacks in CAD patients on propranolol, it did decrease symptom severity and reduce nitroglycerin use. ${ }^{121}$ However, benzodiazepines should generally not be used in elderly patients or those with a history of substance abuse or personality disorders.

$\mathrm{CAD}$ and cardiac risk factors should also be treated aggressively. Smoking cessation should improve both $\mathrm{CAD}$ and panic disorder. Although cholesterol reduction is important, statin therapy has rarely been associated with increased anxiety. Because there is evidence that verapamil ${ }^{122}$ and clonidine ${ }^{123,124}$ have antipanic activity, these drugs may play a specific role in the treatment of hypertension in patients with panic disorder. Although propranolol is recommended after myocardial infarction and may reduce panic symptoms, ${ }^{125}$ it has also been associated with exacerbation of panic disorder. ${ }^{126}$ Finally, the combination of tricyclic antidepressants with nitrates and vasodilators can result in significant orthostatic hypotension. ${ }^{117}$

\section{Conclusion}

Chest pain is a common symptom in primary care patients, often leading to disability and care-seeking. Although both important causes of chest pain, panic disorder and coronary artery disease can coexist. When comorbid, the panic attacks may cause the patient with coronary disease to seek care but could also provoke a cardiac event. Distinguishing between the 2 disorders can be difficult based on clinical criteria alone. If one condition is recognized, a search for the other is warranted because of the potential consequences if left undetected.

We thank E. Mikaila Adams for her technical and editorial assistance.

\section{References}

1. Kroenke K, Mangelsdorff AD. Common symptoms in ambulatory care. Am J Med 1989;86:262-6.

2. Kroenke K, Arrington ME, Mangelsdorff AD. Prevalence of symptoms in medical outpatients and the adequacy of therapy. Arch Intern Med 1990; 150:1685-9.

3. Kroenke K, Spitzer RL, Williams JBW, et al. Physical symptoms in primary care. Predictors of psychiatric disorders and functional impairment. Arch Fam Med 1994;3:774-9.

4. Forrest CB, Nutting PA, Starfield B, Von Schrader S. Family physicians' referral decisions. J Fam Pract 2002;51:215-22.

5. Ambulatory Sentinel Practice Network. Exploratory report of chest pain in primary care. J Am Board Fam Pract 1990;3:143-50.

6. Klinkman MS, Stevens D, Gorenflo DW. Episodes of care for chest pain. J Fam Pract 1994;38:345-52.

7. Katerndahl D, Trammell C. Prevalence and recognition of panic states in STARNET patients presenting with chest pain. J Fam Pract 1997;45:5463.

8. Vitalino PP, Katon W, Maiuro RD, Russo J. Coping in chest pain patients with and without psychiatric disorder. J Consult Clin Psychol 1989;57:33843. 
9. Bass C, Wade C. Chest pain with normal coronary arteries. Psychol Med 1984;14:51-61.

10. Kane FJ Jr, Harper RG, Wittels E. Angina as a symptom of psychiatric illness. South Med J 1988; 81:1412-6.

11. Ho KY, Knag JY, Yeo B, Ng WL. Non-cardiac, non-esophageal chest pain. Gut 1998;43:105-10.

12. Katerndahl DA, Realini JP. Use of health care services by persons with panic symptoms. Psychiatr Serv 1997;48:1027-32.

13. Katerndahl DA, Realini JP. Where do panic attack sufferers seek care?. J Fam Pract 1995;40:237-43.

14. Swinson RP, Cox BJ, Woszcayna CB. Use of medical sevices and treatment for panic disorder with agoraphobia and for social phobia. Can Med Assoc J 1992;147:878-83.

15. Candilis PJ, McLean RS, Otto MW, et al. Quality of life in patients with panic disorder. J Nerv Ment Dis 1999;187:429-34.

16. Katerndahl DA. Symptom severity and perceptions in subjects with panic attacks. Arch Fam Med 2000; 9:1028-35.

17. Yingling KW, Wulsin LR, Arnold LM, Rouan GW. Estimated prevalences of panic disorder and depression among consecutive patients seen in an emergency department with acute chest pain. J Gen Intern Med 1993;8:231-5.

18. Fleet RP, Dupuis G, Marchand A, Burelle D, Beitman BD. Detecting panic disorder in emergency department chest pain patients. Ann Behav Med 1997;19:124-31.

19. Wulsin LR, Hillard JR, Geier P, Hissa D, Rouan GW. Screening emergency room patients with a typical chest pain for depression and panic disorder. Int J Psychiatry Med 1988;18:315-23.

20. Mateos JLA, Perez CB, Carrasco JSD, Olivares D. Atypical chest pain and panic disorder. Psychother Psychosom 1989;52:92-5.

21. Kane FJ Jr, Strohlein J, Harper RG. Noncardiac chest pain in patients with heart disease. South Med J 1991;84:847-52.

22. Dammen T, Arnesen H, Ekeberg O, Husebye T, Friis S. Panic disorder in chest pain patients referred for cardiological outpatient investigation. J Intern Med 1999;245:497-507.

23. Pearce MJ, Mayou RA, Klimes I. Management of atypical non-cardiac chest pain. Q J Med 1990;76: 991-6.

24. Cormier LE, Katon W, Russo J, Hollifield M, Hall ML, Vitaliano PP. Chest pain with negative cardiac diagnostic studies. J Nerv Ment Dis 1988;176: 351-8.

25. Carney RM, Freedland KE, Ludbrook PA, Saunders RD, Jaffe AS. Major depression, panic disorder, and mitral valve prolapse in patients who complain of chest pain. Am J Med 1990;89:757-60.

26. Beitman BD, Lamberti JW, Mukerji V, DeRosear
L, Basha I, Schmid L. Panic disorder in patients with angiographically normal coronary arteries. Psychosomatics 1987;28:480-4.

27. Dammen T, Ekeberg O, Arnesen H, Friis S. Detection of panic disorder in chest pain patients. Gen Hosp Psychiatry 1999;21:323-32.

28. Goldberg R, Morris P, Christian F, Badger J, Chabot S, Edlund M. Panic disorder in cardiac outpatients. Psychosomatics 1990;31:168-73.

29. Chignon JM, Lepino JP, Ades J. Panic disorder in cardiac outpatients. Am J Psychiatry 1993;150: 780-5.

30. Beitman BD, Kushner M, Lamberti JW, Mukerji V. Panic disorder without fear in patients with angiographically normal coronary arteries. J Nerv Ment Dis 1990;178:307-12.

31. Kushner MG, Beitman BD, Beck NC. Factors predictive of panic disorder in cardiology patients with chest pain and no evidence of coronary artery disease. J Psychosom Res 1989;33:207-15.

32. Beitman BD, Basha I, Flaker G, et al. Atypical or nonarginal chest pain. Arch Intern Med 1987;147: $1548-52$.

33. Bass C, Chambers JB, Kiff P, Cooper D, Gardner WN. Panic anxiety and hyperventilation in patients with chest pain. Q J Med 1988;69:949-59.

34. Carter C, Maddock R, Amsterdam E, McCormick S, Waters C, Billet J. Panic disorder and chest pain in the coronary care unit. Psychosomatics 1992;33: 302-9.

35. Katon W, Hall ML, Russo J, et al. Chest pain: relationship of psychiatric illness to coronary arteriographic results. Am J Med 1988;84:1-9.

36. Fleet RP, Dupuis G, Marchand A, Burelle D, Beitman BD. Panic disorder, chest pain and coronary artery disease. Can J Cardiol 1994;10:827-34.

37. Aikens JE, Michael E, Lerin T, Myers TC, Lowry E, McCracken LM. Cardiac exposure history as a determinant of symptoms and emergency department utilization in non-cardiac chest pain patients. J Behav Med 1999;22:605-17.

38. Conti S, Savron G, Bartolucci G, et al. Cardiac neurosis and psychopathology. Psychother Psychosom 1989;52:88-91.

39. Aikens JE, Wagner LI, Lickerman AJ, Chin MH, Smith A. Primary care physician responses to a panic disorder vignette. Int J Psychiatry 1998;28: 179-88.

40. Katerndahl DA. Factors in the panic-agoraphobia transition. J Am Board Fam Pract 1989;2:10-6.

41. Katerndahl DA, Realini JP. Quality of life and panic-related work disability in subjects with infrequent panic and panic disorder. J Clin Psychiatry 1997;58:153-8.

42. Fleet RP, Martel JP, Lavoie KL, Dupuis G, Beitman BD. Non-fearful panic disorder. Psychosom 2000;41:311-20. 
43. Fleet RP, Dupuis G, Kaczorowski J, Marchand A, Beitman BD. Suicidal ideation in emergency department chest pain patients: panic disorder a risk factor. Am J Emerg Med 1997;15:345-9.

44. Realini JP, Katerndahl DA. Factors affecting the threshold for seeking care: the Panic Attack CareSeeking Threshold (PACT) study. J Am Board Fam Pract 1993;6:215-3.

45. Katerndahl DA. Factors associated with persons with panic attacks seeking medical care. Fam Med 1990;22:462-6.

46. Salvador-Carulla L, Segui J, Fernandez-Cano P, Canet J. Costs and offset effect in panic disorders. Br J Psychiatry Suppl 1995;166 (Suppl 27):23-8.

47. Ross CA, Walker JR, Norton GR, Neufeld K. Management of anxiety and panic attacks in immediate care facilities. Gen Hosp Psychiatry 1988;10: 129-31.

48. Greenland S. Quantitative methods in the review of epidemiologic literature. Epidemiol Rev 1987; 9:1-30.

49. De Silva RA, Bachman WR. Cardiac consultation in patients with neuropsychiatric problems. Cardiol Clin 1995;13:225-39.

50. Cope RL. Psychogenic factor in chest pain. Tex Med 1969;65:78-81.

51. Sox HC Jr, Hickam DH, Marton KI, et al. Using the patient's history to estimate the probability of coronary artery disease: a comparison of primary care and referral practices [published erratum appears in Am J Med 1990;89:550]. Am J Med 1990; 89:7-14.

52. Fleet RP, Dupuis G, Marchand A, et al. Panic disorder in coronary artery disease patients with noncardiac chest pain. J Psychosom Res 1998;44: 81-90.

53. Chernen L, Friedman S, Goldberg N, Feit A, Kwan $\mathrm{T}$, Stein R. Cardiac disease and nonorganic chest pain. Cardiology 1995;86:15-21.

54. Bajwa WK, Asuis GM, Sanderson WC, Irfan A, Van Praag HM. High cholesterol levels in patients with panic disorder. Am J Psychiatry 1992; 149:376-8.

55. Roy-Byrne PP, Stein MB, Russo J, et al. Panic disorder in the primary care setting: comorbidity, disability, service utilization, and treatment. J Clin Psychiatry 1999;60:492-9.

56. Bystristsky A, Maidenberg E, Craske MG, Vapnik T, Sharpino D. Laboratory psychophysiological assessment and imagery exposure in panic disorder patients. Depress Anxiety 2000;12:102-8.

57. Katon WJ. Chest pain, cardiac disease, and panic disorder. J Clin Psychiatry 1990;51 Suppl:27-30.

58. Davies SJ, Ghahramani P, Jackson PR, et al. Association of panic disorder and panic attacks with hypertension. Am J Med 1999;107:310-6.

59. Katon W. Panic disorder and somatization. Am J Med 1984;77:101-6.
60. Weissman MM, Markowitz JS, Ouellette R, Greenwald S, Kahan JP. Panic disorder and cardiovascular/cerebrovascular problems. Am J Psychiatry 1990;147:1504-8.

61. Noyes R Jr, Claney J, Hoenk PR, Slymen DJ. Prognosis of anxiety neurosis. Arch Gen Psychiatry 1980;37:173-8.

62. Goodwin RD, Hamilton SP. Panic attack as a marker of core psychopathological processes. Psychopathology 2001;34:278-88.

63. Chambers J, Bass C. Chest pain with normal coronary anatomy. Prog Cardiovasc Dis 1990;33: 161-84.

64. Hayward C, Taylor CB, Roth WT, King R, Agras WS. Plasma lipid levels in patients with panic disorder or agoraphobia. Am J Psychiatry 1989;146: 917-9.

65. Shioiri T, Fujii K, Someya T, Takahashi S. Serum cholesterol levels and panic symptoms in patients with panic disorder. J Affect Dis 2000;58:167-20.

66. Peter H, Hand I, Hohagen F, et al. Serum cholesterol level comparison: control subjects, anxiety disorder patients, and obsessive-compulsive disorder patients. Can J Psychiatry 2002;47:557-61.

67. Breslau N, Klein DF. Smoking and panic attacks. Arch Gen Psychiatry 1999;56:1141-7.

68. Amering $M$, Bankier B, Berger $\mathrm{P}$, Grieng IH, Windhauler J, Katschnig H. Panic disorder and cigarette snaking behavior. Compr Psychiatry 1999; 40:35-8.

69. Vessicchio JC, Termine A, George TP. Smoking cessation and panic attacks. J Clin Psychiatry 2002; 63:594-5.

70. Basha I, Mukerji V, Langerin P, Kushner M, Alpert M, Beitman BD. Atypical angina in patients with coronary artery disease suggest panic disorder. Int J Psychiatry Med 1989;19:341-6.

71. Beitman BD. Panic disorder in patients with angiographically normal coronary arteries. Am J Med 1992; 92:33S-40S.

72. Beitman BD, Mukerji V, Lamberti JW, et al. Panic disorder in patients with chest pain and angiographically normal coronary arteries. Am J Cardiol 1989;63:1399-403.

73. Katerndahl DA. Illness attitudes and coping process in subjects with panic attacks. J Nerv Ment Dis 1999;187:562-6.

74. Kroeze S, Van Den Houst MA. Selective attention for cardiac information in panic patients. Behav Res Ther 2000;38:63-72.

75. Aikens JE, Zvolensky MJ, Eifert GH. Differential fear of cardiopulmonary sensations in emergency room noncardiac chest pain patients. J Behav Med 2001;24:155-67.

76. Lynch P, Bakal DA, Whitelaw W, Fung T. Chest muscle activity and panic anxiety. Psychosom Med 1991;53:80-9. 
77. Fleet R, Lavoie K, Beitman BD. Is panic disorder associated with coronary artery disease? J Psychosom Res 2000;48:347-56.

78. Smith MG, Hecker JE. Prevalence of panic disorder in post-myocardial infarction patients. Int J Rehabil Health 1997;3:197-204.

79. Roy-Byrne PP, Schmidt P, Cannon RO, Diem H, Rubinow DR. Microvascular angina and panic disorder. Int J Psychiatry Med 1989;19:315-25.

80. Coryell W, Noyes R, Clancy J. Excess mortality in panic disorder: a comparison with primary unipolar depression. Arch Gen Psychiatry 1982;139:701-3.

81. Kawachi I, Sparrow D, Vokonas PS, Weiss ST. Symptoms of anxiety and risk of coronary heart disease. Circulation 1994;90:2225-9.

82. Taylor CB, King R, Ehlers A, et al. Treadmill exercise test and ambulatory measures in panic attacks. Am J Cardiol 1987;60:48J-52J.

83. Kahn JP, Gorman JM, King DL, Fyer AJ, Liebowitz MR, Klein DR. Cardiac left ventricular hypertrophy and chamber dilatation in panic disorder patients. Psychiatr Res 1990;32:55-61.

84. Schmidt NB, Lerew DR, Santiago H, Trakowski JH, Staab JP. Effects of heart-rate feedback on estimated cardiovascular fitness in patients with panic disorder. Dep Anx 2000;12:59-66.

85. Kahn JP, Drusin RE, Klein DF. Idiopathic cardiomyopathy and panic disorder. Am J Psychiatry 1987;144:1327-30.

86. Magni G, Borgherini G, Canton G. Idiopathic cardiomyopathy and panic disorder in cardiac transplant candidates [letter]. Am J Psychiatry 1988;145: 902-3

87. Griez EJL, Mammar N, Loirat JC, Djega N, Trochut JN, Bouhour JB. Panic disorder and idiopathic cardiomyopathy. J Psychosom Res 2000;48:585-7.

88. Benjamin AB, Adityanjee MBBS, Wright J. Aortic aneurysm in the differential for panic attacks. Psychosomatics 2000;41:282-3.

89. Sietsema KE, Simon JI, Wasserman K. Pulmonary hypertension presenting as a panic disorder. Chest 1987;91:910-2.

90. Katerndahl DA. Panic and prolapse. J Nerv Ment Dis $1993 ; 181: 539-44$.

91. Savage DD, Devereux RB, Garrison RJ, et al. Mitral valve prolapse in the general population. 2 . Clinical features: the Framingham Study. Am Heart J 1983;106:577-81.

92. Mavissakalian M, Salerni R, Thompson ME, Michelson L. Mitral valve prolapse and agoraphobia. Am J Psychiatry 1983;140:1612-4.

93. Dager SR, Cowley DS, Dunner DL. Biological markers in panic states. Biol Psychiatry 1987;22: 339-59.

94. Grunhaus L, Gloger S, Birmacher B. Clomipramine treatment for panic attacks in patients with mitral valve prolapse. J Clin Psychiatry 1984;45: 25-7.

95. Devereux RB, Kramer-Fox R, Shear MK, Kligfield $\mathrm{P}$, Pini R, Savage DD. Diagnosis and classification of severity of mitral valve prolapse: methodologic, biologic, and prognostic considerations. Am Heart J 1987;113:1265-332.

96. Klein DF, Gorman JM. Panic disorders and mitral valve prolapse (monograph). J Clin Psychiatry 1984;2:14-7.

97. Ballenger JC, Gibson R, Peterson GA, Laraia MT. "Functional" MVP in agoraphobia/panic disorder. Presented at the 139th Annual Meeting of the American Psychiatric Association, Washington, DC, 1986.

98. Gorman JM. Panic disorder; focus on cardiovascular status. Presented at the 139th annual meeting of American Psychiatric Association in Washington, DC, 1986.

99. Balon R, Ortiz A, Pohl R, Yeragani VK. Heart rate and blood pressure during placebo-associated panic attacks. Psychosom Med 1988;50:434-8.

100. Yeragani VK, Balon R, Pohl R, et al. Decreased $\mathrm{R}-\mathrm{R}$ variance in panic disorder patients. Acta Psychiatr Scand 1990;81:554-9.

101. Middleton HC. Cardiovascular dystonia in recovered panic patients. J Affect Dis 1990;19:229-36.

102. Yeragani VK, Pohl R, Balon R, Jung I, Kaneus R. Heart rate in panic disorder [letter]. Acta Psychiatr Scand 1991;83:79.

103. Shear MK, Kligfield P, Harshfield G, et al. Cardiac rate and rhythm in panic patients. Am J Psychiatry 1987;144:633-7.

104. Goldberger AL, Rigney DR, Mietus J, Antman EM, Greenwald S. Nonlinear dynamics in sudden cardiac death syndrome. Experientia 1988;44: 983-7.

105. Reis SE, Holubkov R, Smith AJC, et al. Coronary microvascular dysfunction is highly prevalent in women with chest pain in the absence of coronary artery disease. Am Heart J 2001;141:735-41.

106. Braunwald E, Zipes DP, Libby P, editors. Heart disease, 6th ed. New York: WB Saunders; 2001.

107. Gallerani M, Manfredini R, Mele D, et al. Can panic disorder be considered as an angina equivalent? Eur Heart J 1995;16:2013-4.

108. Pollack MH, Kradin R, Otto MW, et al. Prevalence of panic in patients referred for pulmonary function testing at a major medical center. Am J Psychiatry 1996;153:110-3.

109. Dammen T, Ekeberg O, Arnesen H, Friis S. Personality profiles in patients referred for chest pain. Psychosomatics 2000;41:269-76.

110. Jeejeebhoy FM, Dorian P, Newman DM. Panic disorder and the heart. J Psychosom Res 2000;48: 393-403.

111. Maunder RG. Panic disorder associated with gas- 
trointestinal disease: review and hypotheses. J Psychosoma Res 1998;44:91-105.

112. Beitman BD, Basha IM, Trombka LH, et al. Pharmacotherapeutic treatment of panic disorder in patients presenting with chest pain. J Fam Pract 1989; 28:177-80.

113. Wulsin LR, Maddock R, Beitman B, Dawaher R, Wells NE. Clonazepam treatment of panic disorder in patients with recurrent chest pain and normal coronary arteries. Int J Psychiatry Med 1999;29:97105.

114. Krishnan KR. Chest pain and serotonin. Gastroenterology 2001;121:493-4.

115. Goodacre S, Mason S, Arnold J, Angelini K. Psychologic morbidity and health-related quality of life of patients assessed in a chest pain observation unit. Ann Emerg Med 2001;38:369-76.

116. Wulsin L, Liu T, Storrow A, Evans S, Dewan N, Hamilton C. Randomized, controlled trial of panic disorder treatment initiation in an emergency department chest pain center. Ann Emerg Med 2002; 39:139-43.

117. Taylor CB, Hayward C. Cardiovascular considerations in selection of antipanic pharmacotherapy. J Psychiat Res 1990;24:43-9.

118. Thase ME. Effects of venlafaxine on blood pressure: a meta-analysis of original data from 3744 depressed patients. J Clin Psychiatry 1998;59: $502-8$.
119. Stratton JR, Halter JB. Effect of a benzodiazepine (Alprazolam) on plasma epinephrine and norepinephrine levels during exercise stress. Am J Cardiol 1985;56:136-9.

120. Shioiri T, Fujii K, Someya T, Takahashi S. Effects of pharmacotherapy on serum cholesterol levels inpatients with panic disorder. Acta Psychiatr Scand 1996;93:164-7.

121. Mendels J, Chernoff RW, Blatt M. Alprazolam as an adjunct to Propranolol in anxious outpatients with stable angina pectoris. J Clin Psychiatry 1986; $47: 8-11$.

122. Klein E, Uhde TW. Controlled study of verapamil for treatment of panic disorder. Am J Psychiatry 1988;145:431-4.

123. Liebowitz MR, Fyer AJ, McGrath P, Klein DF. Clonidine treatment of panic disorder. Psychopharmacol Bull 1981;17:122-3.

124. Uhde TW, Stein MB, Vittone BJ, et al. Behavioral and physiologic effects of short-term and long-term administration of clonidine in panic disorder. Arch Gen Psychiatry 1989;46:170-7.

125. Kathol R, Noyes R, Slyman D, Crowe R, Clancy J, Kerber R. Propranolol in chronic anxiety disorders. Arch Gen Psychiatry 1980;37:1361-5.

126. Levinson DF, Acquaviva J. Exacerbation of panic disorder during propranolol therapy. J Clin Psychopharmacol 1988;8:193-5. 